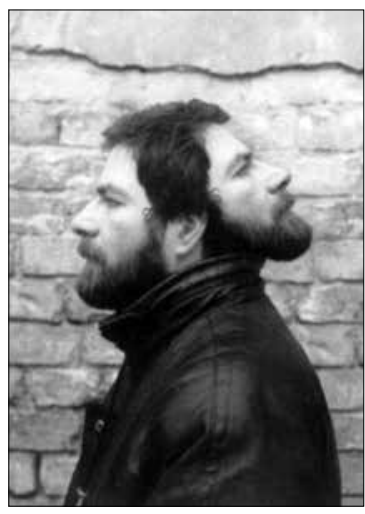

Tapyba
Painting

https://doi.org/10.24101/logos.2017.29

ALEKSANDRAS VOZBINAS

\title{
TAPYTOJAS \\ ALEKSANDRAS VOZBINAS
}

Gimė 1958 m. Vilniuje. 1976 m. baigè Vilniaus m. 22 vid. mokyklą, 1976-1979 m. mokèsi Šiaulių pedagoginiame institute, 1979-1981 m., 1982-1988 m. studijavo Valstybiniame dailès institute (dabar Vilniaus dailès akademija), kurią baigęs igijo tapytojo-pedagogo kvalifikaciją. Dalyvauja parodose nuo 1988 m., yra dalyvavęs daugiau nei 100 ịvairių parodų Lietuvoje ir užsienyje. Daug metų organizavo tarptautinị projektą "Soutine dienos" ir tarptautines konferencijas.

\section{Painter Aleksandras Vozbinas}

Aleksandras Vozbinas was born in Vilnius, in 1958. In 1976 he graduated form Vilnius High School Nr. 22. From 1976 till 1981, Vozbinas studied at Šiauliai University. In 1982 he started studies in Fine Arts Institute (now Vilnius Fine Arts Academy) from which he graduated in 1988 with qualification of teacher and painter. Since then, he regularly exhibits his paintings in Lithuania and abroad. From 1998 till 2010 Vozbinas organized international project The Days of Soutine. Also he organizes various cultural events, international conferences, publishes articles on various topics of culture. 


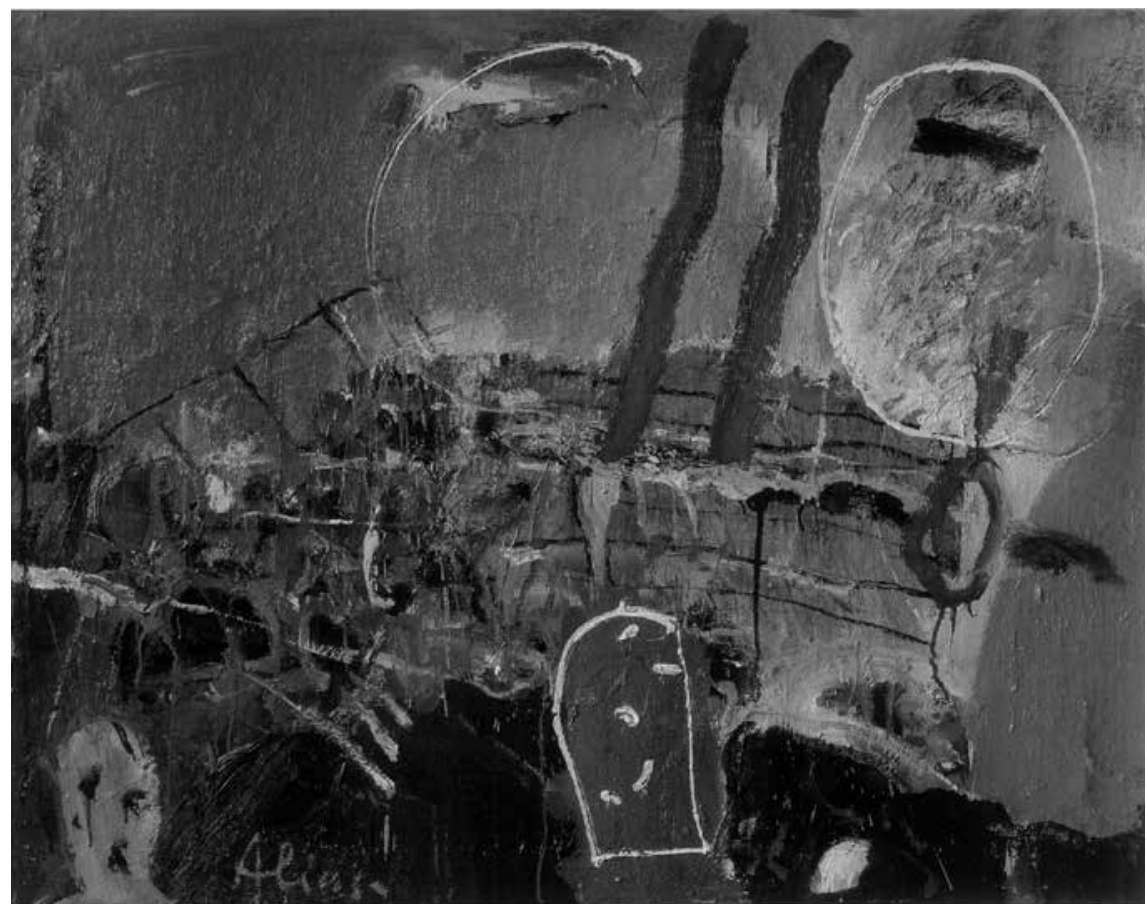

A. VOZBINAS. Tarp dienos ir vakaro. 1993. Drobė, aliejus. $80 \times 100$

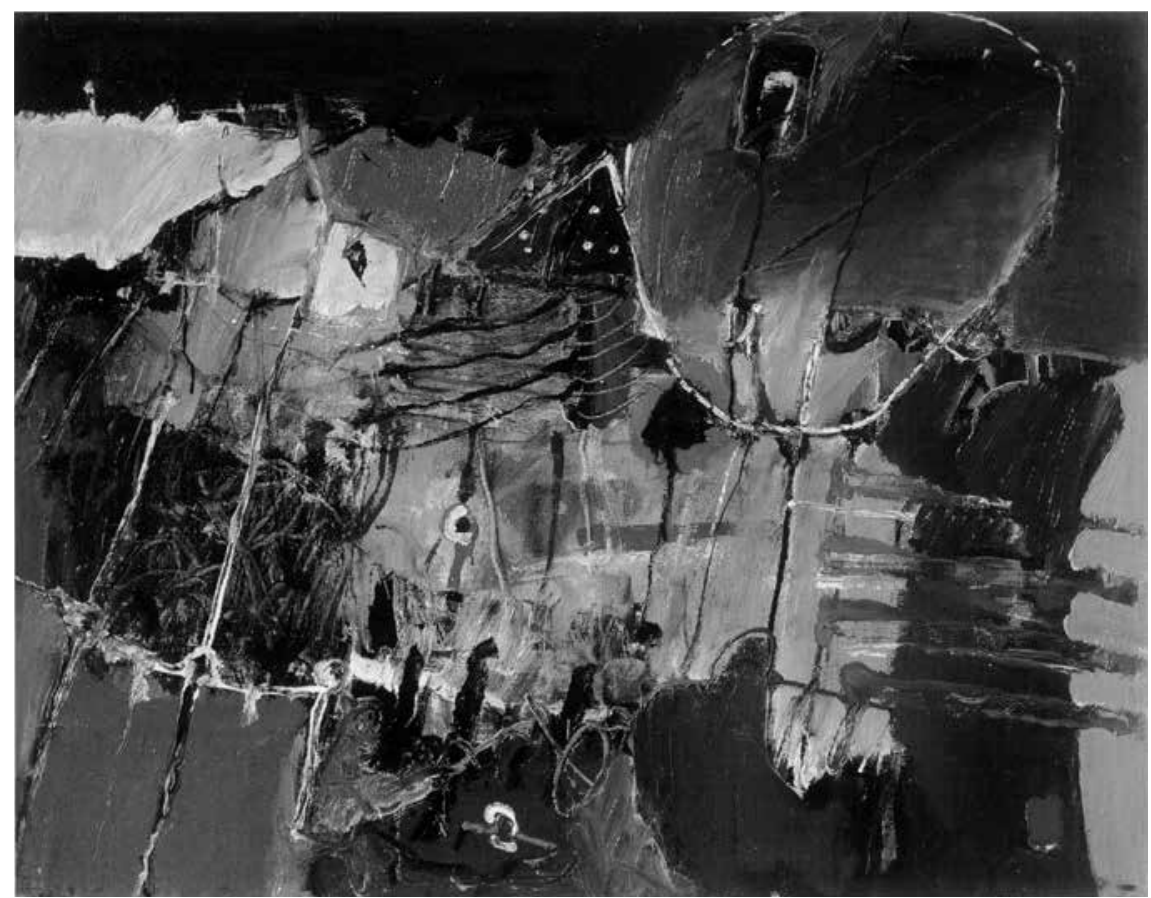

A. VOZBINAS. Vasaros naktis. 1997. Drobè, aliejus. $80 \times 100$

LOGOS 91 


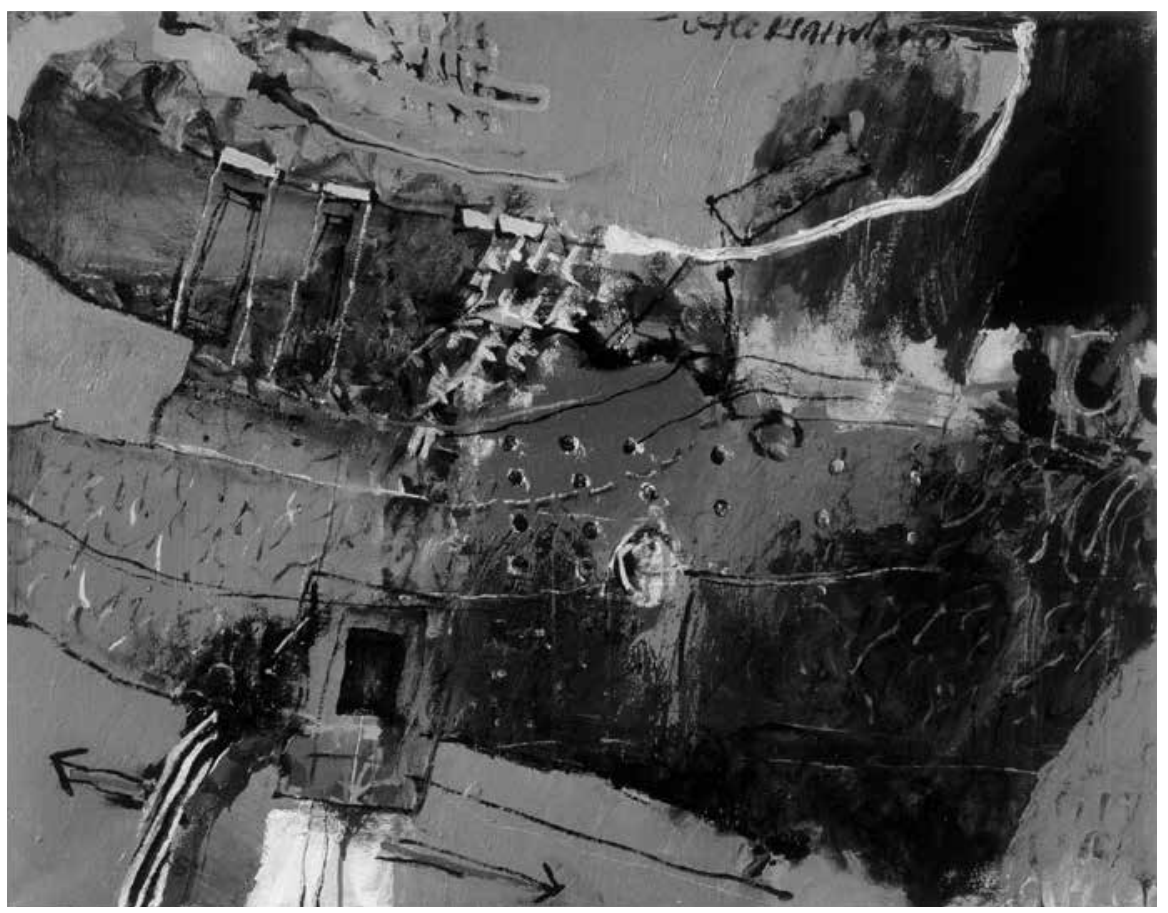

A. VOZBINAS. Vasaros pilis. 2003. Drobė, aliejus. $80 \times 100$

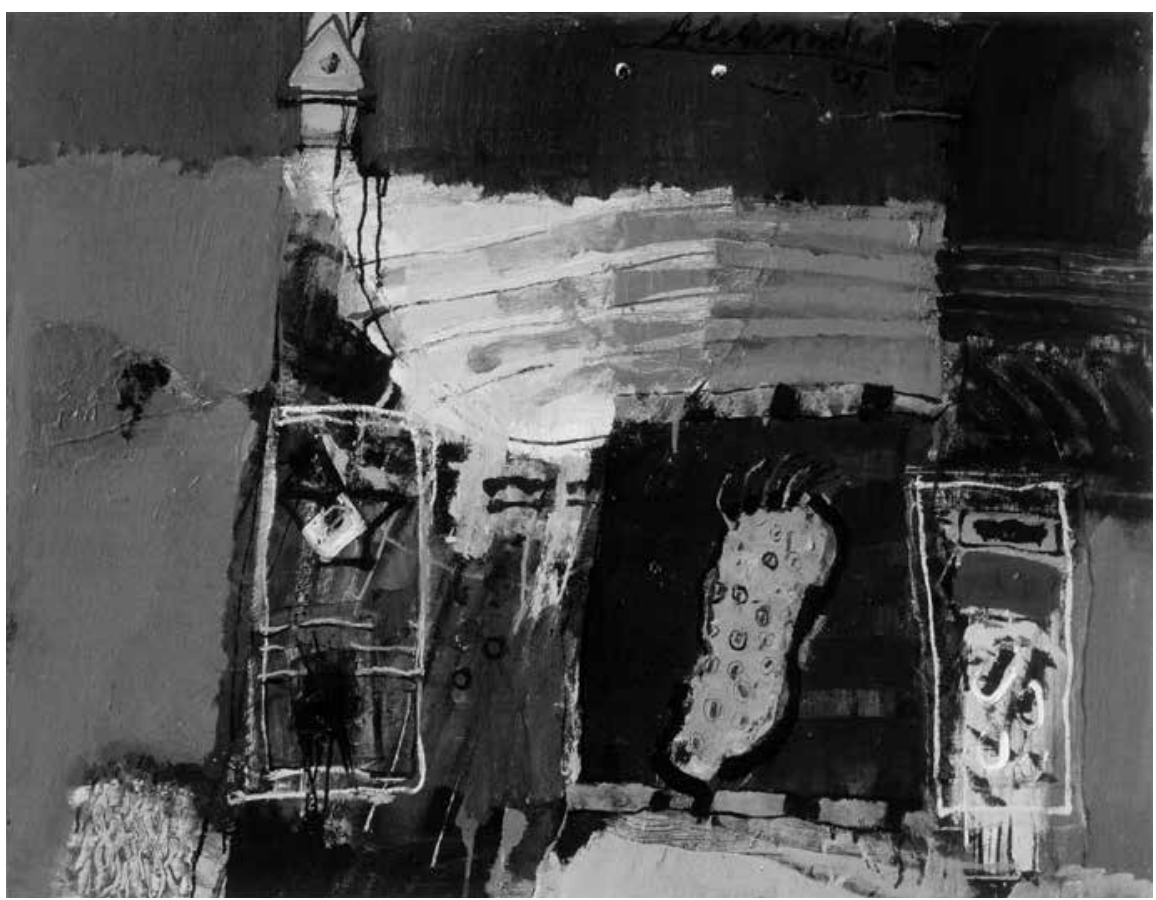

A. VOZBINAS. Dedikacija Umberto Eco. 2003. Drobè, aliejus. $80 \times 100$ 


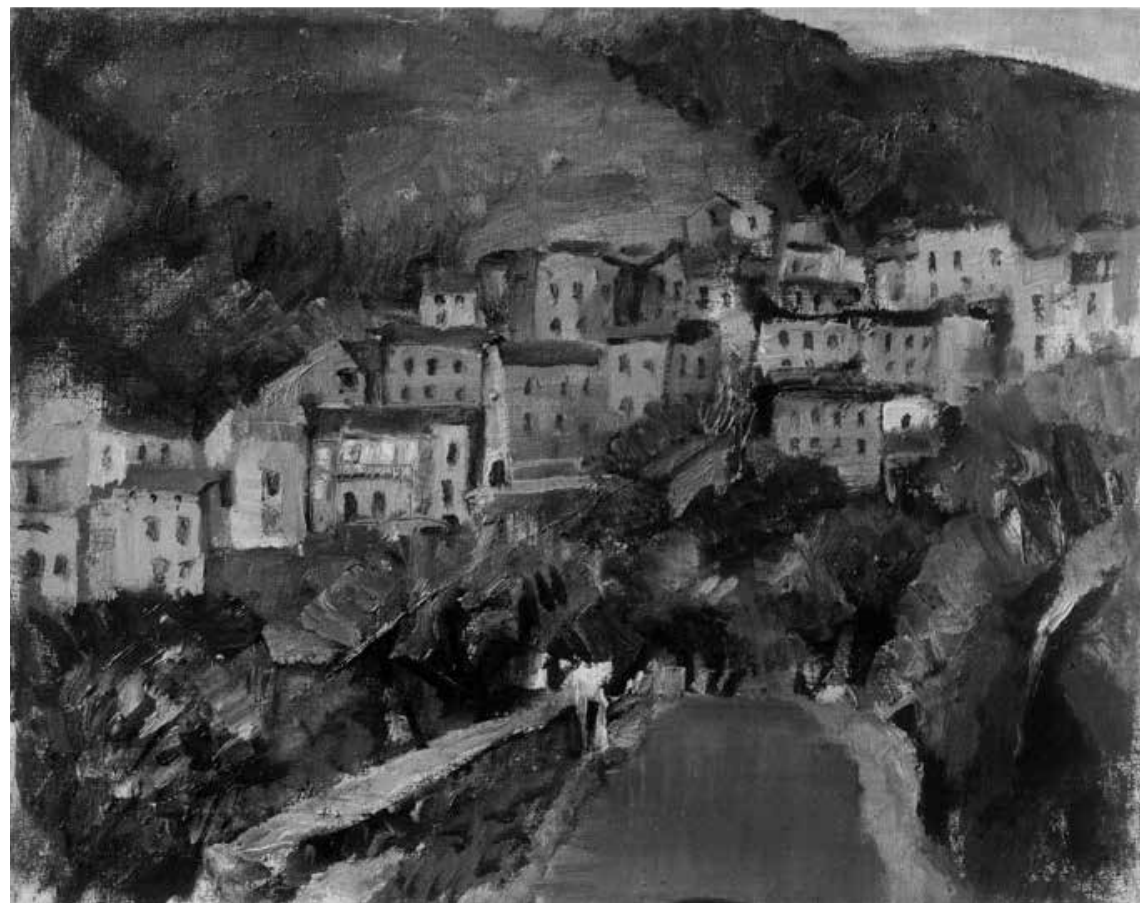

A. VOZBINAS. Korsikos motyvas. 2006. Drobè, aliejus. $40 \times 50$

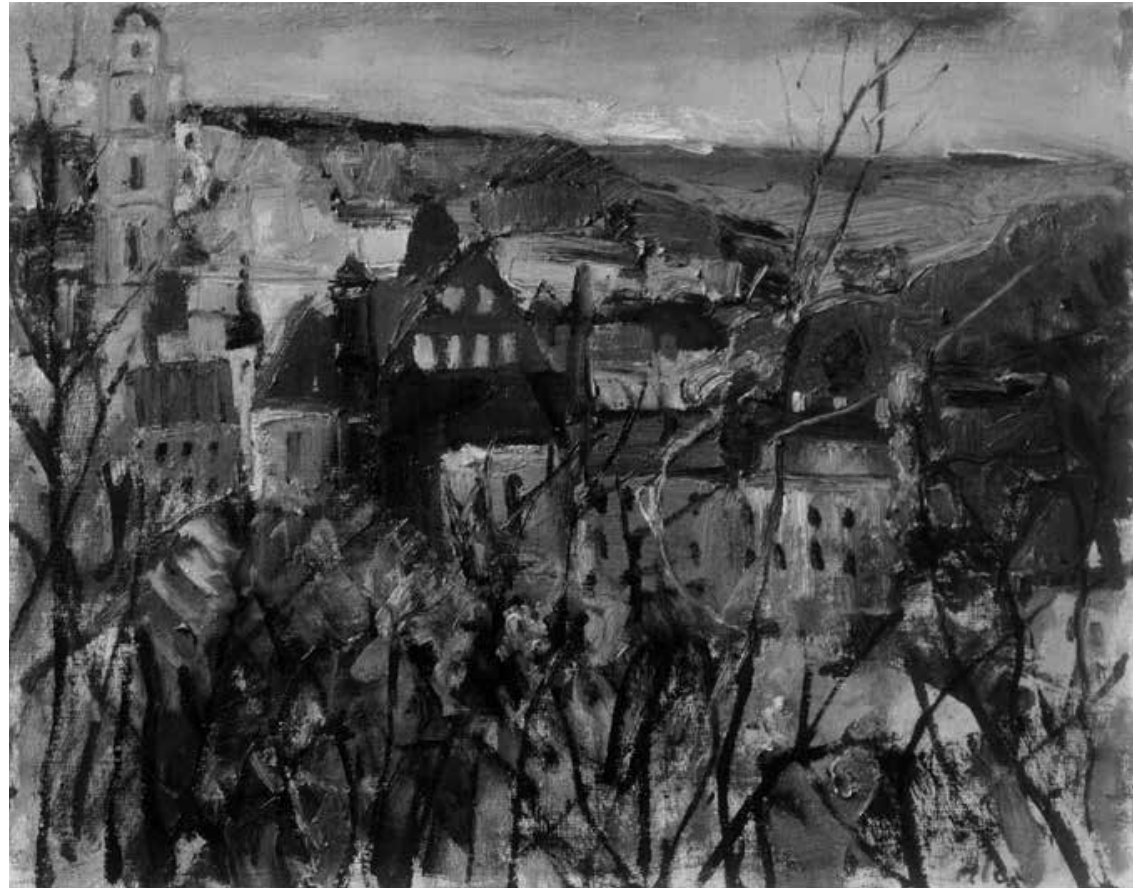

A. VOZBINAS. Vilnius pavasari. 2006. Drobè, aliejus. $40 \times 50$

LOGOS 91 


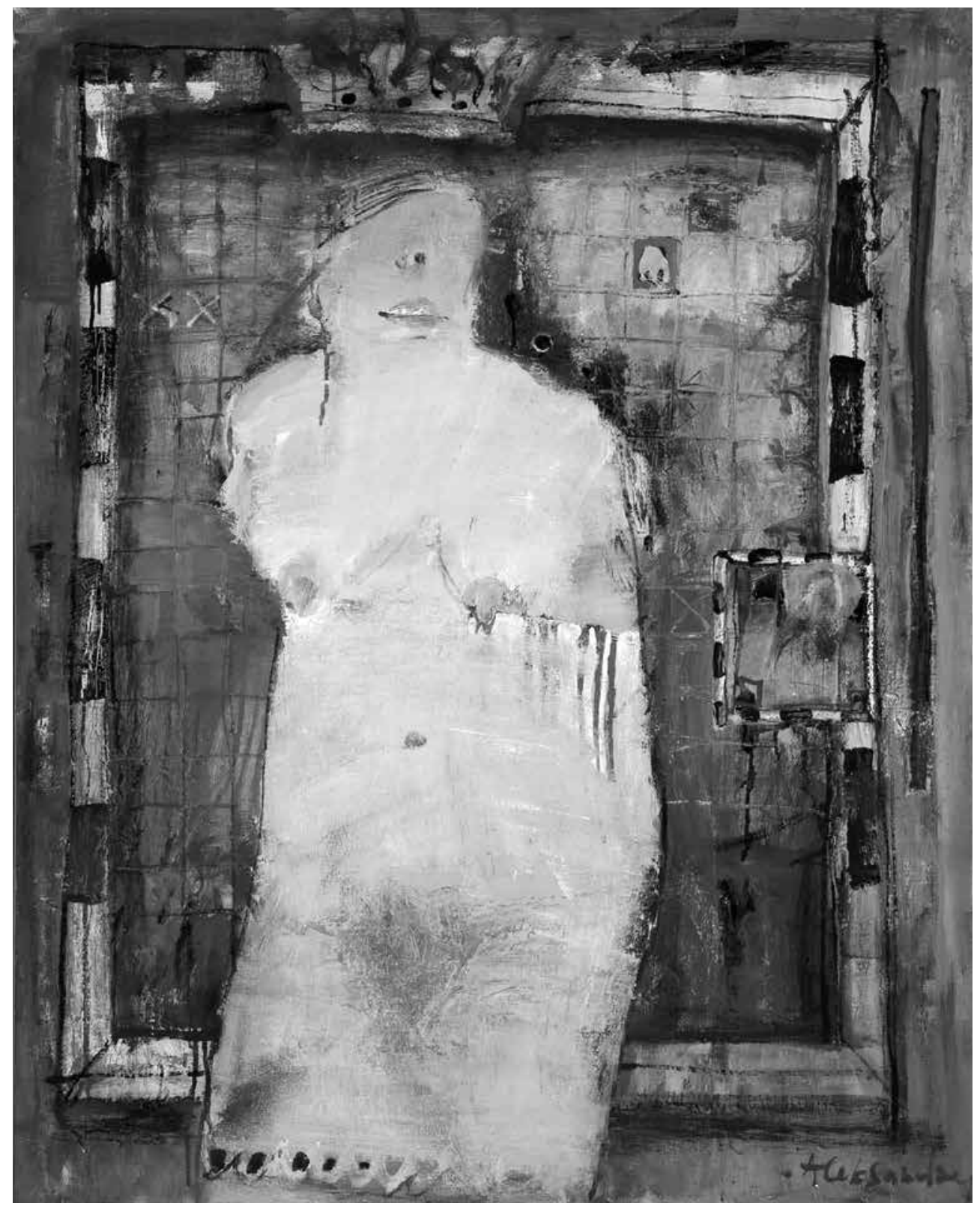

A. VOZBINAS. Karalienės Barboros vakaras. 2005. Drobė, aliejus. $100 \times 80$ 


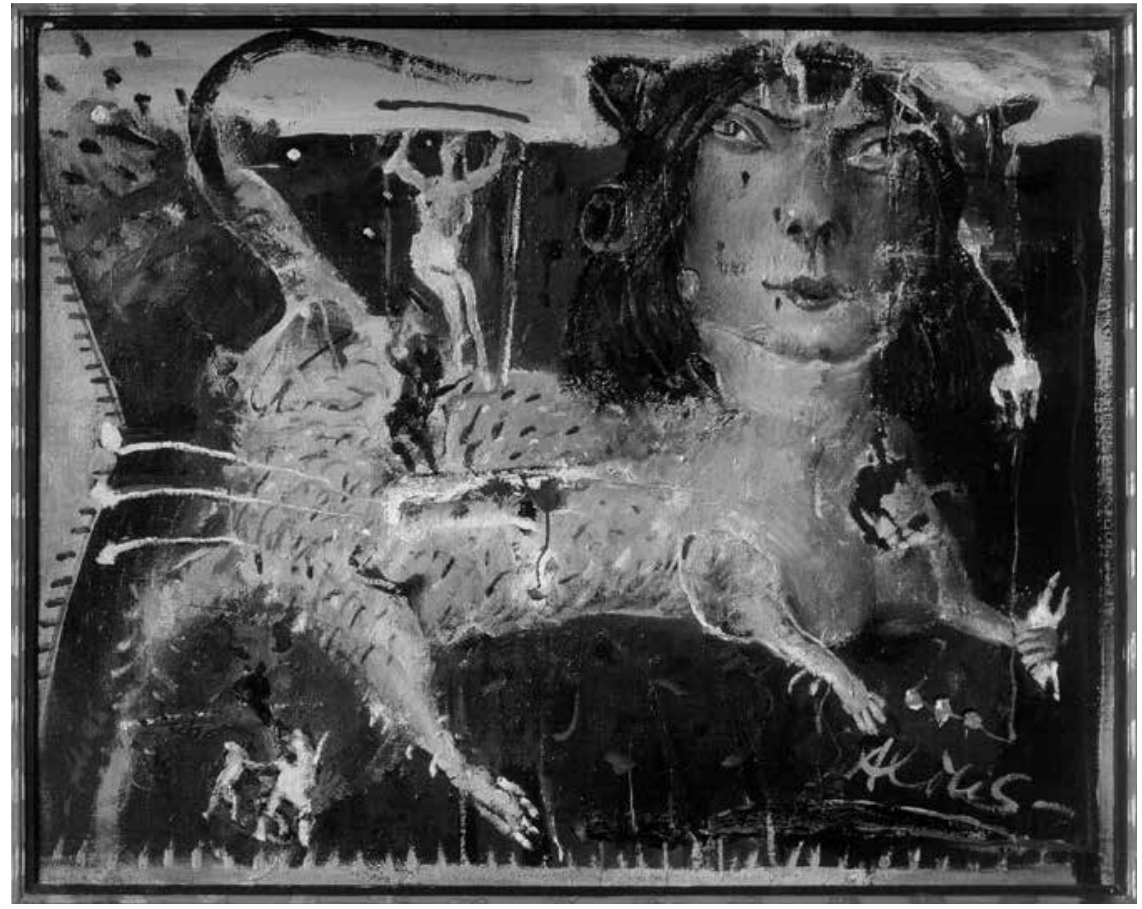

A. VOZBINAS. Heraldinis motyvas I. 1993. Drobė, aliejus. $80 \times 100$

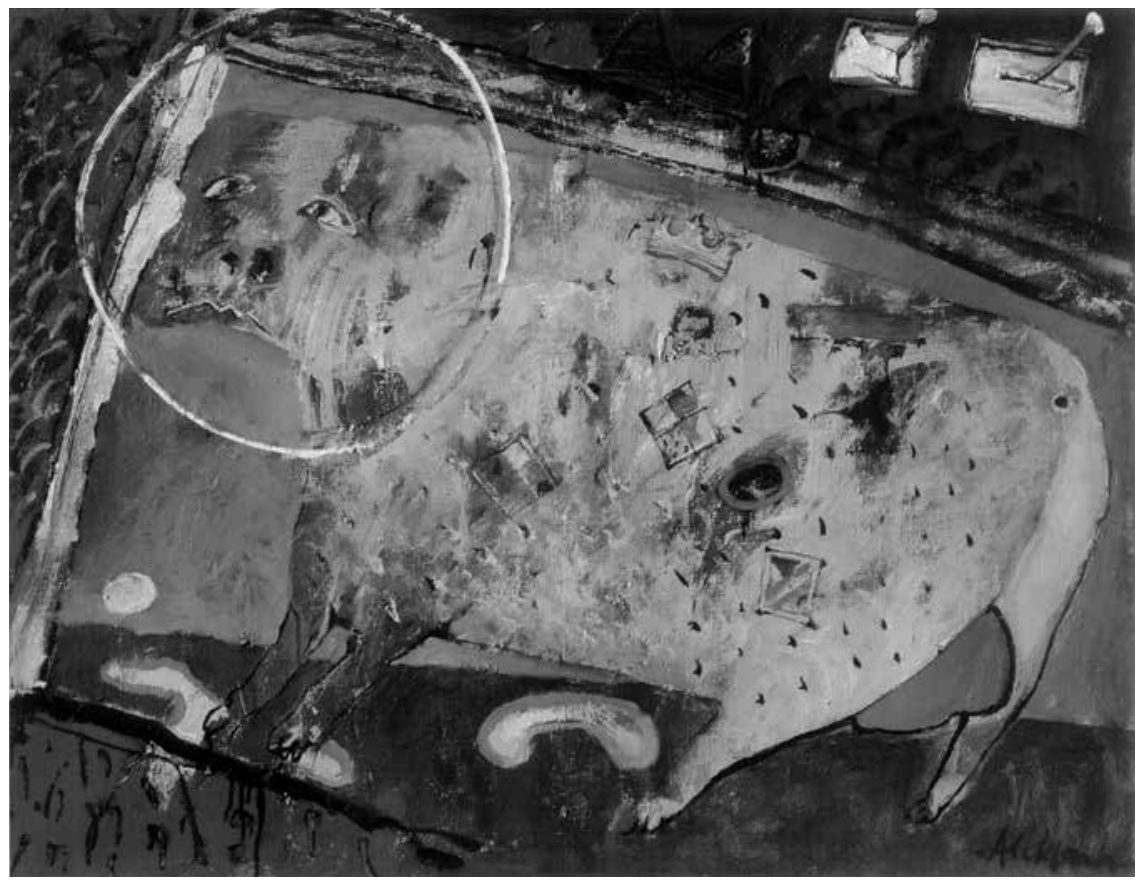

A. VOZBINAS. Šventoji būtybè. 2006. Drobè, aliejus. $92 \times 73$ 


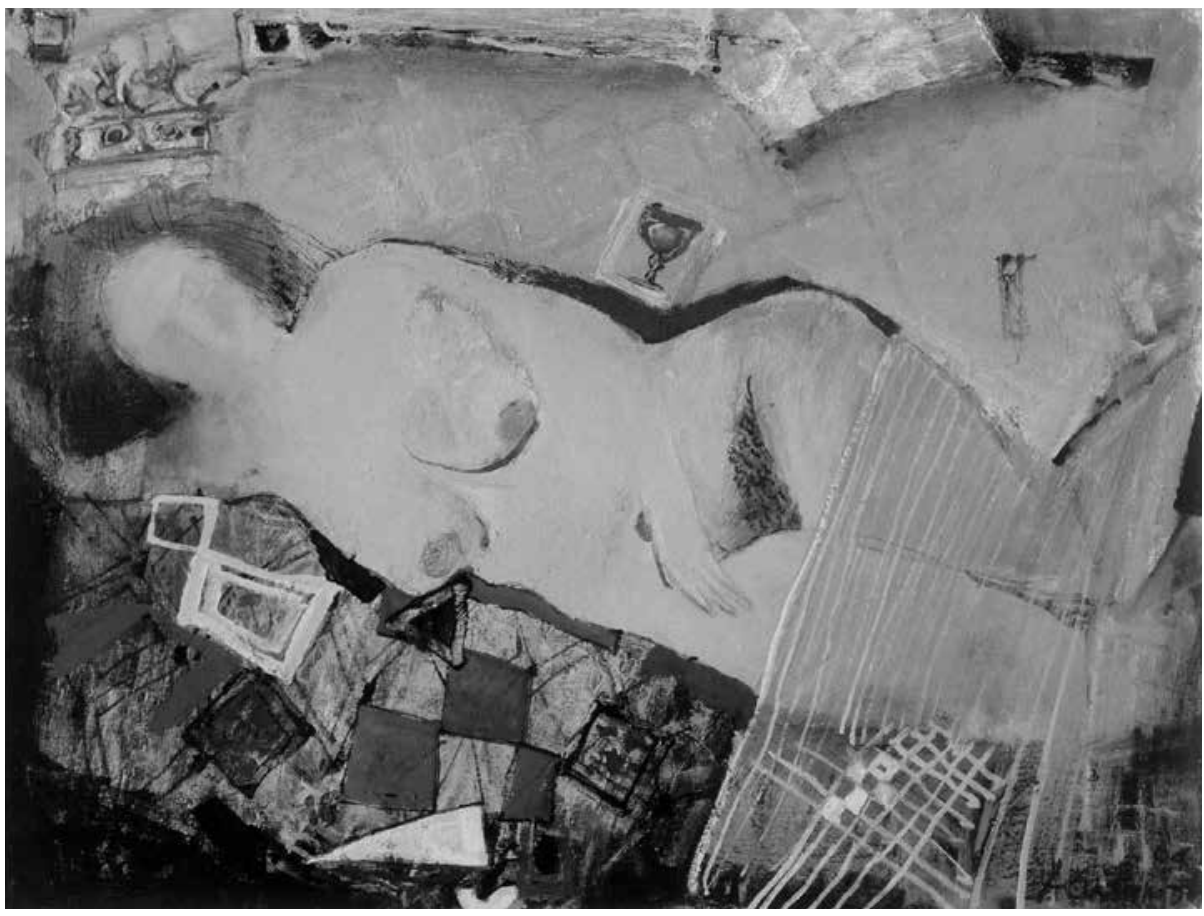

A. VOZBINAS. Karalienès sapnas. 2005. Drobė, aliejus. $73 \times 92$

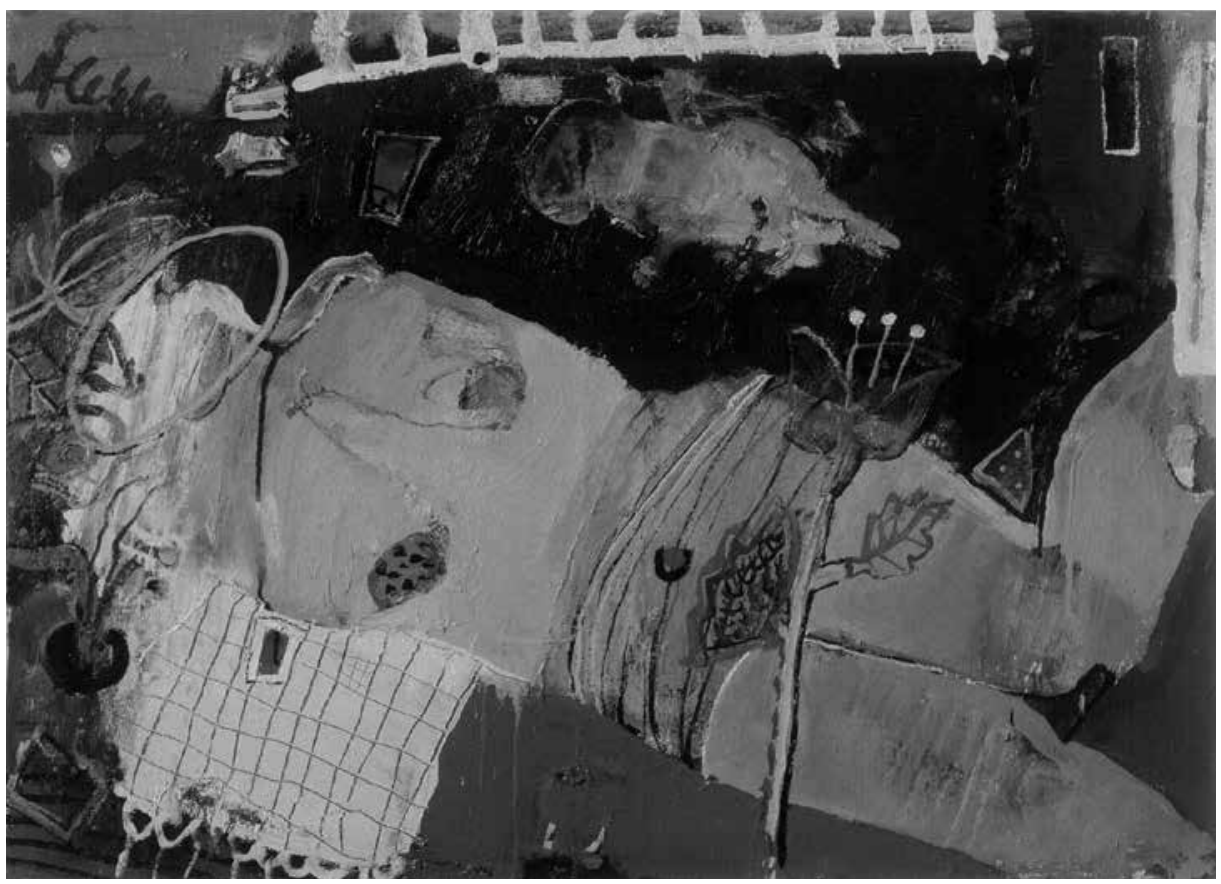

A. VOZBINAS. Gimimo diena. 2004. Drobė, aliejus. $73 \times 92$ 


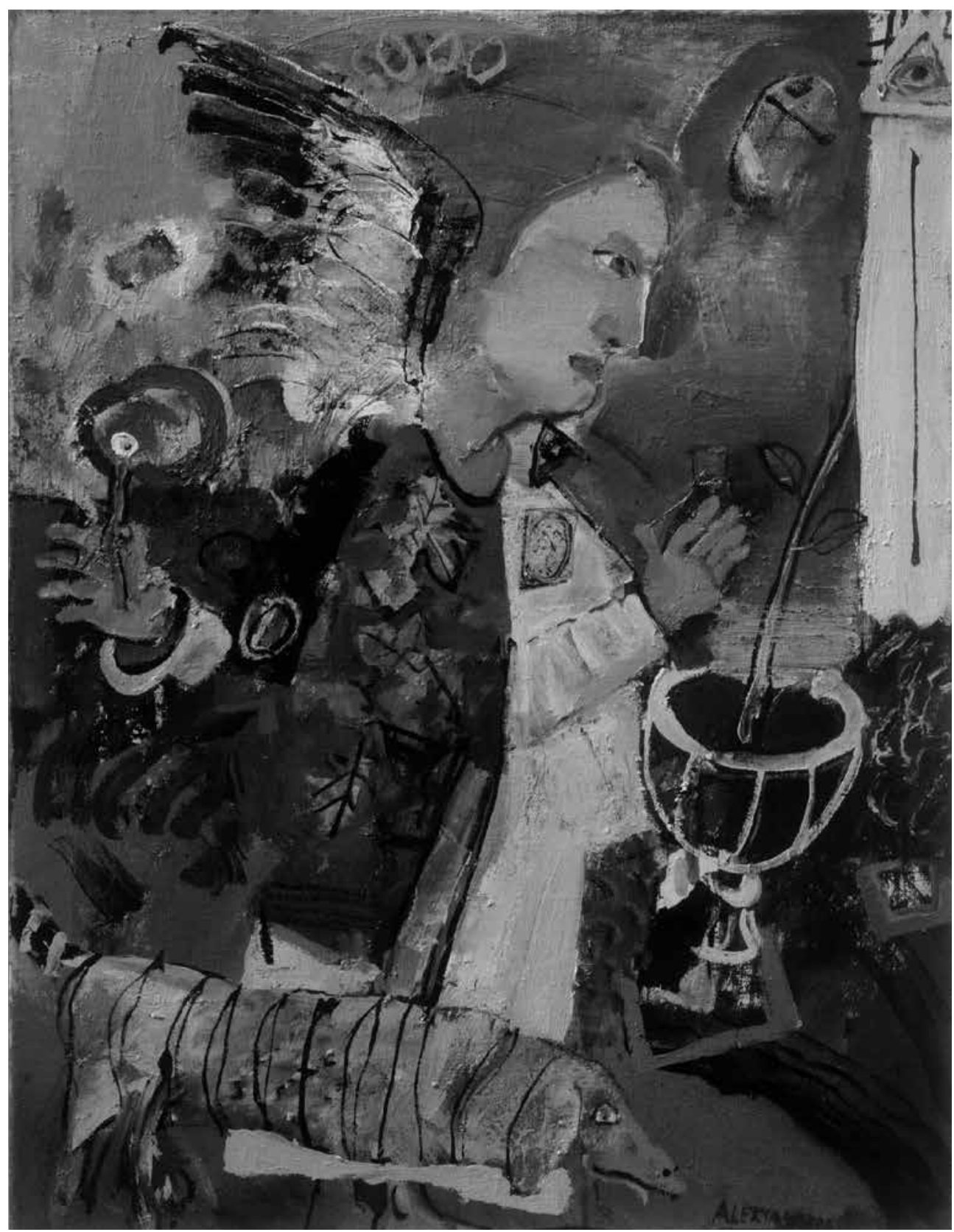

A. VOZBINAS. Angelas su šuniuku. 2005. Drobè, aliejus. $73 \times 64$ 